\title{
Changing Social Structure in Europe calls for Tailor-made, Barrier-free Living and new Interior Design
}

\author{
Carsten Brausch $^{1}$, Dušan Katunský ${ }^{2}$ \\ ${ }^{1}$ LVR - Integrationsamt Landschaftsverband Rheinland, Köln, Germany \\ ${ }^{2}$ Faculty of Civil Engineering, Institute of Architectural Engineering, Technical University of Kosice, Slovakia \\ e-mail: Carsten.Brausch@lvr.de,dusan.katunsky@tuke.sk
}

\begin{abstract}
Europe is experiencing a demographic change, resulting in a change in social structure. People are living longer and birth rates are declining. This changing structure in Europe poses special challenges for housing designers and builders. A new approach in the design of real estate must be created and implemented that caters for the future needs of the occupants of the living space in all phases and allows residents to remain self-sufficient in their "home" for as long as possible. In the earliest stages of design, the typical requirements for each phase of life of future, potential residents must already be considered. This is especially true for people with special protection needs, such as those with visual or hearing impairments.
\end{abstract}

Key words: Demographic Change; Barrier-free Design; Living Space in Europe; Life- Stage- Specific Needs; Modular Home Design.

\section{Introduction}

In the European states a change in the social structure can be observed. Life expectancy has increased dramatically within the last 50 years. Due to the improved living situation and an advanced level of medical care people are getting older. With advancing age the probability of experiences with various limitations like visual impairment, reduced hearing or physical abilities is increasing.

In such a living phase tenants are often forced to leave their long-time living space, as these homes cannot serve the "new" individual needs and the resulting personal protection objectives. This move from the privacy of their own home into new surroundings is often experienced as a painful change. They are taken out their familiar and well-known surrounding because their homes cannot be modified to serve the new needs. It has to be the 
task of politics to establish a new inclusive social space and demand of architects and designers to establish new aims for the design of housing.

Representative of different European cultures Germany and Slovakia were chosen to be further analyzed in this paper. Germany should represent the Western European Societies with already advanced demographic changes and well-established ways of building, while Slovakia should represent a Central European Society, which currently is at the beginning of its demographic changes and has the opportunity to initiate building changes at an earlier time point of this development. Therefore the focus of this work is on data available from these two representative countries, with limited supporting data from other sources.

\section{Materials and methods}

The surveys presented in this paper and the ensuing discussions are based on a review of the literature. The following research consists of the study of existing publications, literature and numerous accessible data, and reflects the current state of knowledge of demographic development and barrier-free living space in Europe. The results of questionnaires and fieldwork carried out in Slovakia and Germany pinpoint the specific requirements and special need of user groups of different ages at different stages of life. In the frame of the field research questionnaires were distributed to 60 people of varying age. 30 were distributed in Slovakia, 30 in Germany. The survey shall provide an overview about the awareness regarding housing and living space. Based on the replies to 13 questions, statements on opinion, needs and way of dwelling will be made. The analysis of the results shall provide an interpretation on the needs and commercial viability of a modular and flexible living space design for all phases of life.

The response to the questions by the subjects took place without a special introduction on the topic of demographic change and its consequences on design of living space. Questioning professional specialists was avoided as these are not representative for regular users due to their high level of professional association with the real estate market. Due to space limitations, further details regarding the questionnaires can be found in the thesis [1].

The various requirements are mapped.

\section{Results}

For the survey to be effective, it was important to illustrate the importance of housing within Europe, to define the concept of barrier-free accessibility and to consider the current social structure. Evaluation of the specific needs of the individual occupants can determine the criteria that need to be considered when planning a tailored living space.

It is essential that the survey emphasize the importance of housing in European society. It is clear that the house is more than protection against climatic conditions and an individual retreat for people and families. The importance of housing in Europe has changed. "Living manner and home decor represent social affiliation, societal norms and dispositions of material and cultural resources" [2]. 
In much of the EU, the home is seen as the center of private life and plays an important role, far beyond the original protective one. The private living space is a projection of the own identity.

\section{$>$ "Tell me how you live}

and I will tell you who you are" [3]

Moving into a home of one's own is a crucial step in gaining personal independence. People tend to daydream about the design of their first home many times before finally making it a reality. We envisage a variety of needs and desires, which we then must adapt, due to the harsh confines of space and money, to our own "personal style". Lifestyle, taste and personality characterize the functional and aesthetic design of the living space. Living manner and home decor also represent social affiliation, societal norms and disposition of material and cultural resources [3].

The demographic trend is changing the social structure in Europe, thus altering the medium and long-term development requirements of living space users. Planners and designers of housing would be well advised to consider these needs in order to avoid vacancies and create tailored living spaces that allow residents to remain independent for as long as possible in their "own home".

Demographic change is a primary topic in the EU, as it is becoming more and clearer that this change will shape society. The decision-makers in the parliaments of the member states are being called upon to take action.

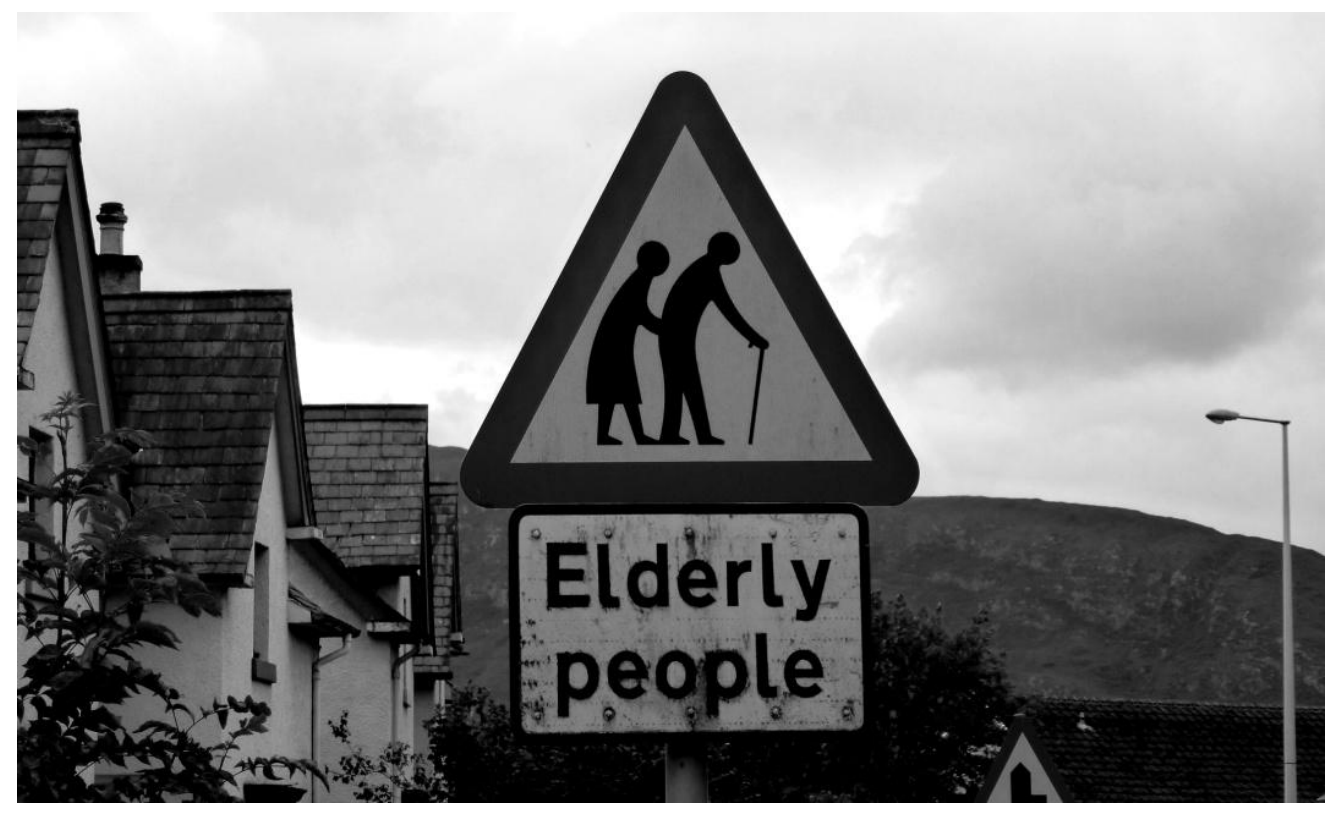

Fig. 1 Fort William, Schottland 2012, Carsten Brausch 
The changing average age of society with an ever-increasing life expectancy on one side, is opposed by a lower birth rate on the other side. Statistically, the life expectancy of newborns increases each year in Europe by two to three months. People are not only living longer, but they also have increasing demands [4].

Of fundamental importance for the survey is the definition of the term "barrier-free living space". A survey of the current literature and related media quickly shows that the concept of accessibility is not clearly defined and is very versatile. It is therefore essential to clarify the way the author views "accessibility".

Some of the differences in interpretation are caused by the translation from English. The concept of accessibility, itself, is a not well defined; hence, in the literature there are several terms used to represent it. Some of the terms listed in the figure below are use for specific customer groups, such as the elderly or disabled.

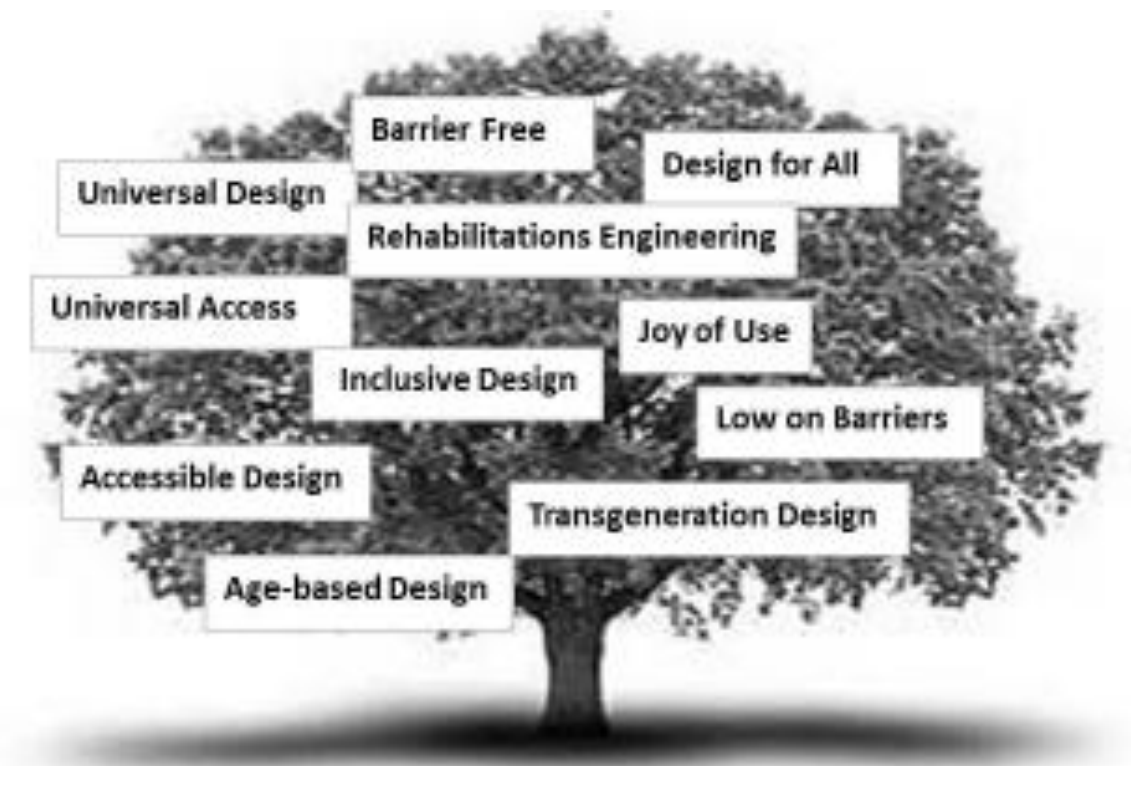

Fig 2 Definition Tree, Carsten Brausch

All of these terms embody the concept of accessibility and require a barrier-free design which is based on the needs of the people. In the following, the terms "barrier-free design", and "design for all" are considered both to mean the ability to use housing without external support, and for all people independent of life stage, age or health status. For consistency, the author will use the term "barrier-free design" throughout.

„Design for all is:

Design for

- Human diversity,

- Social inclusion,

- Equality “[5] 
As a basis for the design and construction of custom-fit, barrier-free housing, the planner must take into account the specific and individual needs of different user groups. In addition to the basic requirements, the needs of those with special protection objectives must be considered.

The motivation of man is characterized by the various life stages and living requirements change accordingly. For example, young parents need an additional child's room and space for a pram. And even a temporary change in health, for example due to a sports injury, can reduce the accessibility of an existing property that is not barrier-free.

„Whether with prams,

Legs in plaster or crutches -

Once in our lives,

We all encounter barriers"[6]

Of particular importance in the design of barrier-free housing are people with disabilities. The needs-based design enables independent living and participation at all stages of life.

The WHO (World Health Organization) created a classification to describe the functional health status, type and degree of disability, social impairment and relevant environmental factors of people under the name "International Classification of Functioning, Disability and Health (ICF)". A disability in the context of the ICF is the result of negative interaction between a person with a health problem and contextual factors on that person's ability to function. [7]

An analysis of the questionnaires led to the following assignment of participants in age groups:

\section{Classification in Age Groups Participants in \%}

up to 35 years $\quad 35$ to 50 years $\quad$ more than 50 years

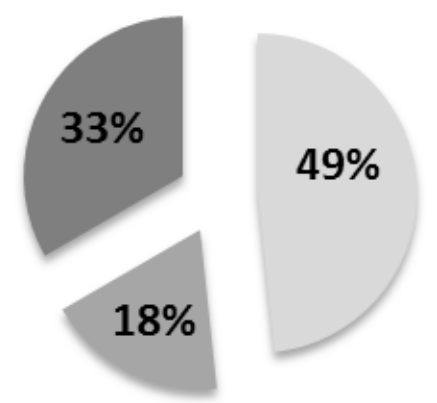

Fig. 3 Classification in age groups, participants in percent, Carsten Brausch 
The desire to remain in their current living quarters for as long as possible was deemed to be very important to $32 \%$ of respondents and important to $59 \%$ of the respondents.

\section{The Ability to Stay in the Current Living Quarters}

\section{$\square$ very important $\square$ important $\mathbf{Q}$ less important $\square$ not important}

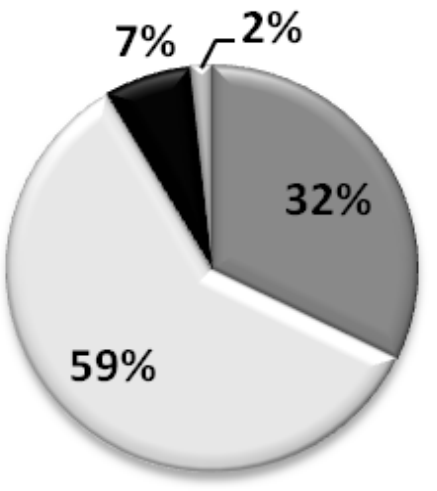

Fig. 4 The ability to stay in the current living quarters, Carsten Brausch

In order to fulfill this desire, housing planners and designers must develop a tailor-made form of housing.

The survey incurred on the basis of the completed questionnaires showed that the needs of the users change in the respective phases of life.

Older people tend to have greater safety objectives, and thus greater requirements for the living space. However, as the following example shows, this cannot be generalized.

The young family requires more space to park a pram, while the older person requires that same amount of space to park a collator. Basically, it can be assumed that with age comes the possibility of more impairment and thus more special requirements for the living space.

People with disabilities are of special significance in the planning of housing, because their requirements are greater, independent of their stage of life. Accordingly, some of these needs are exemplified in the following radar diagram.

As will be apparent from the network diagram, different target groups have different requirements for their living space. For example, those under 35 years of age rank free movement area the highest on a scale of 1-5. This probably takes into account the increased need for space to store a pram. 
Those over 50 years of age also require a lot of free movement area because they may become dependent crutches or walkers in the future. Visually impaired users, however, have no need for more space.

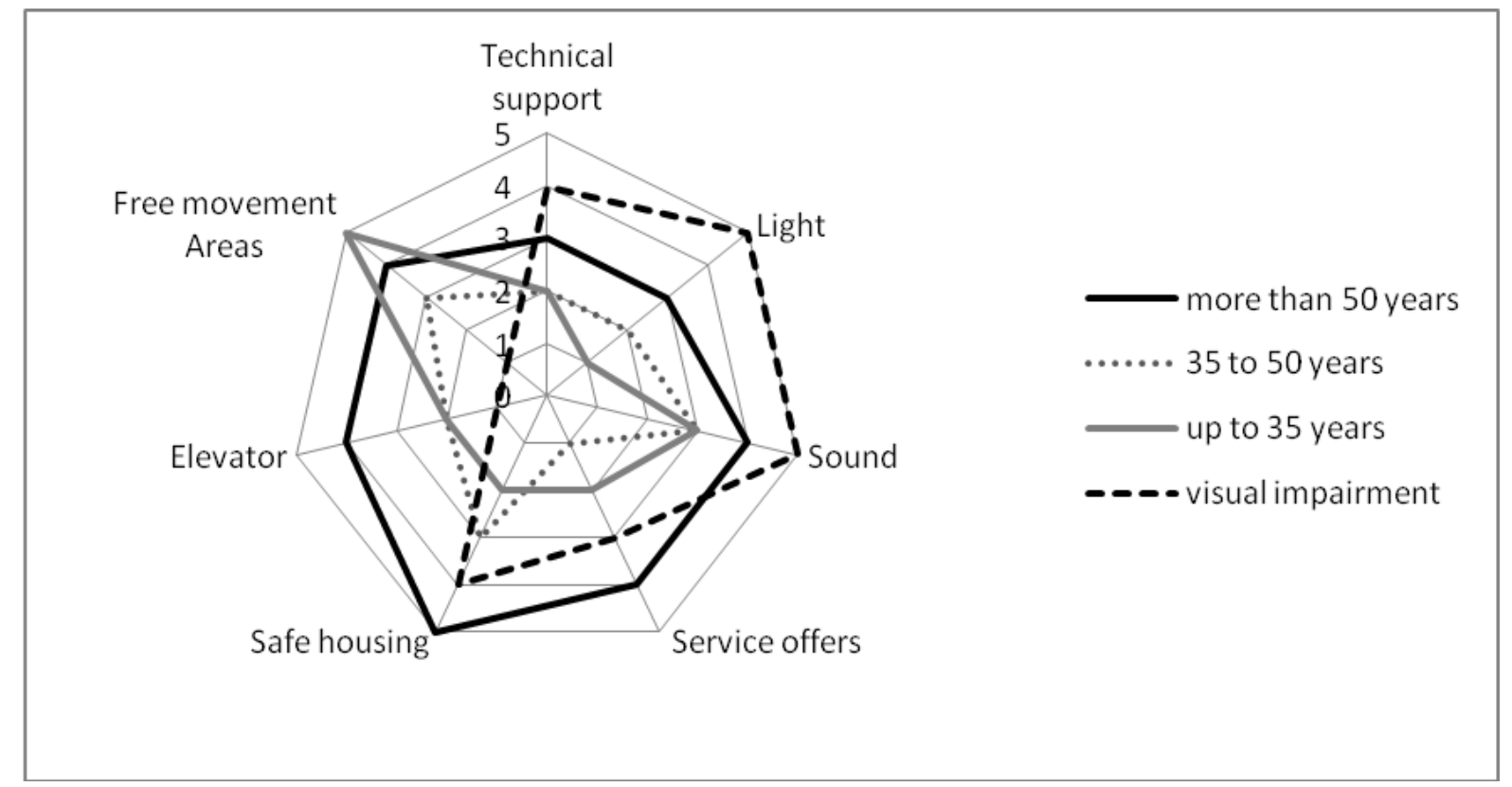

Fig. 5 Individual requirements classification in different groups, Carsten Brausch

To implement a tailored living space, the planner must know and consider the potential needs of any user early on. Needs-based planning will offer investors a unique position in the housing market as providers of tailor-made housing, assuring long-term occupancy and the promise of future income.

In accordance with the signed UN CRPD, Europe must have the political will to provide individuals with the opportunity to live independently in their "own home" for as long as possible, and this at a reasonable price.

As outlined below, a National Science Foundation study in Switzerland "No obstructions in francs and centimes" demonstrates the feasibility of this.

In new buildings, obstacle-free construction adds less than two percent to the cost of construction. However, this demands effort on the part of the project team. Each supplementary request by the owner and any changes made by the executive architect will increase the cost. It is most advantageous to plan a building from the beginning to be accessible to all users, as this adds an average of only 1.8 percent to the construction costs, making it the less expensive option [8].

\section{Discussion}

Planners and designers must take into account the individual needs of future users in their design. The user requirements can be very different, because user needs and abilities can vary greatly according to age, gender, cultural background and physical and mental condition. 
Very few people correspond to the statistical average, the majority deviates from this for the short- or long-term, independent from ageing [9].

Already in planning stage, a variety of changes in the needs of the occupants must be anticipated to be able to set the course. Planners must take into account the probability of the onset of visual and auditory impairments as well as back pain and difficulty walking.

In the European landscape more frequently retirement homes or designer lofts are encountered. Certainly some of these also offer the above outlined advantages and advertise with accessibility, but many of those residencies are no longer financially viable for large sections of society. But since this is just a steadily growing current social and political task of economic considerations special attention needs to be paid. The basic need for sustainable housing must be enabled for all classes of society. In today's terms of housing one must of course also consider the energy aspects. The use of renewable energies and ecological materials ensures long-term rental of the property. By using the latest technology and intelligent control the running cost can be reduced. This energy costs are now a selection argument in finding accommodation often referred to as "second rent".

The difficulty for planners and designers is that at the early stages of planning, they often do not yet know the individual occupant and his/her personal requirements. By considering the potential life-stage-specific needs of the occupant, the planner will be able to incorporate many of the requirements.

The earlier action is taken in the planning stages, the greater the potential control and the lower the costs of implementation.

„Incorporating barrier-free planning from the outset adds very little to the overall cost of construction, whereas relying sole on subsequent adaptations increases costs many times over"[6].

The added value of the barrier-free planning approach to designing a tailored living space is made clear in the survey. "A barrier-free accessible environment (and this also applies to property) is considered by approximately 10 percent of the population to be vital for comfort and for about 30 to 40 percent of the population to be a mark of quality“"[10].

For planners and designers, the problem is to visual housing for the next 50 years, even when, as in most cases, the individual occupants are not known. Implementing a barrier-free design allows better planning of suitable accommodation for a wide spectrum of occupants with a wide spectrum of needs.

It is not possible to predict and allow for every possible event and individual need of the occupant. What is possible and therefore advisable, is to plan the living space so that it is flexible and can be adapted, or transformed, through the use of technology to suit future needs. 


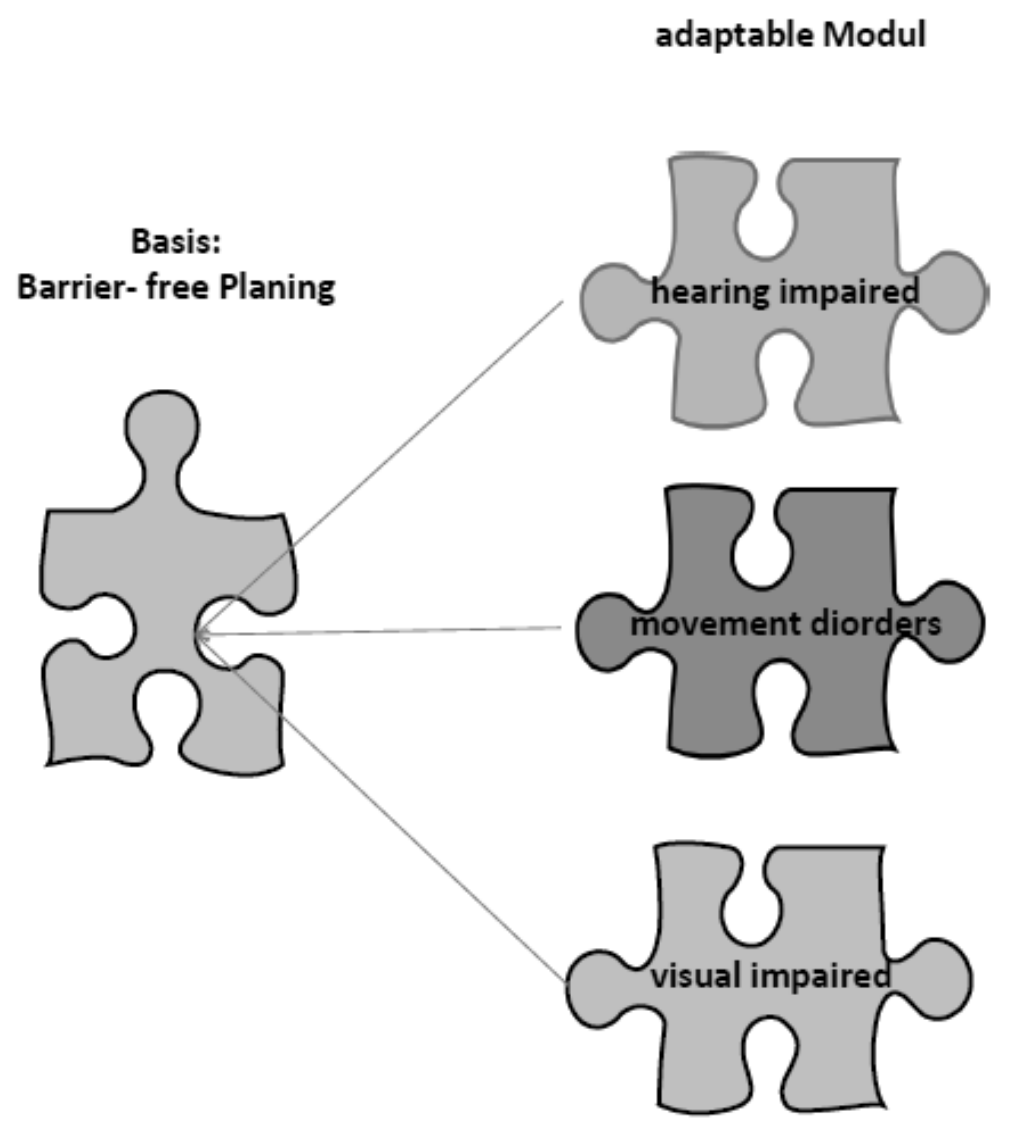

Fig. 6 Adaptable, modular home design, Carsten Brausch

The goal of the future must be to improve on the good approaches to make living spaces generally usable for all potential occupants across all stages of life. This can only be achieved through flexible and customizable living space designs that represent a simplification for architects and become a standard in the medium term.

This can be added to the "basis" of barrier-free design through the use of individual modules. The occupant with impaired hearing can be alerted visually to the doorbell, telephone or kitchen appliances. The visually impaired can have voice input environmental control devices. Occupants with impaired mobility can control windows by pressing a button and have installations retrofitted with handles and lifts. However, some structural and technical foundations need to be in place to allow this.

\section{Acknowledgement}

On the basis of these findings, the co-author will conduct research to develop a methodological approach to the planning of barrier-free housing as part of a PhD- study at the Technical University of Kosice. 


\section{References:}

[1] Brausch, C. (2014). Advantages and Feasibility of a Modular Home Design for All Phases of Life. Written part of $\mathrm{PhD}$ thesis exam, Technical University of Košice, Faculty of Civil Engineering, Slovakia.

[2] Fritzenwallner, R. (2005). Wertentwicklung von Wohnimmobilien in Österreich. Unpublished doctoral dissertation, Donau Universität Krems, Kuchl, Germany.

[3] Häußermann, H., Siebel, W. (1996). Soziologie des Wohnens. München: Juventa Verlag Weinheim und München.

[4] In Würde Altern. (2007). Deutsche Bauzeitung, p. 35.

[5] Stockholm Declaration EIDD. (2004). Sweden.

[6] Kopf, K., Kanzian, D. (2011). Die wahren Barrieren sind im Kopf. Konstruktiv. 260, 12-15.

[7] Loeschke, G. et al., (2012). In Barrierefreies Bauen - Band 1 - Kommentar zu DIN 18040-1. Berlin: Beuth Verlag, p. 21.

[8] Hindernisfrei in Rappen und Franken. (2004). Schweizerische Fachstelle für behindertengerechtes Bauen. Zürich, 3-4.

[9] Bundesministerium für Wirtschaft und Technologie. (2010). Strategiemappe "Zukunftsmarkt 50 plus". Münster, Faktenblatt 3, p. 3.

[10] Krajewski, C. (2009): Von Barrierefreiheit zum Design für Alle Erfahrung aus Forschung und Praxis, hg. Arbeitsgemeinschaft Angewandte Geographie Münster e.V., 2, p. 12 Auflage Münster.

[11] Hakoš, V. (2010). Barrier - free environment - Kitchen and Bathroom as Living Space In Young scientist 2010, 13-15 April 2010 (pp. 1-7). Tatranská Štrba, Slovakia: TU Košice.

[12] Hakoš, V. Šika, P. (2011). The mobility of handicapped people in dwelling houses. In the 13th International Scientific Conference: Current Issues of Civil and Environmental Engineering, 7-9 September 2011 (pp 1-10). Herl'any, Slovakia: TU Košice.

[13] Galajdova,A. et al. (2009). Testing of e-services for seniors and people with disabilities within e-inclusion project MonAMI. International Journal of Rehabilitation Research. Vol. 32(1), S75-S76.

[14] Šimšík,D. et al. (2009). Wearable non-invasive computer controlled system for improving of seniors gait. International Journal of Rehabilitation Research. Vol. 32(1), p. 35.

[15] Šimšík,D. Galajdová,A. Gorlický,M. (2012). Ergonomical aspects in design of mechatronical rehabilitation device. Journal of Biomechanics. Vol. 45(1), p. 71.

[16] Šimšík,D. et al. (2004). Contribution to investigation of pre-surgical rehabilitation effectiveness for total hip endoprostheses patients. International Journal of Rehabilitation Research. Vol. $27(1)$, p. 87.

[17] Živčák,J. et al. (1997). Electronic processing of local muscle disposition sensor output. International Journal of Microcircuits and Electronic Packaging. Vol. 20(1), 41-45. 